\title{
LOS EXTRANJEROS EN EL SEÑORÍO DE VIZCAYA Y EN LA VILLA DE BILBAO A FINALES DEL ANTIGUO RÉGIMEN: ENTRE LA ACEPTACIÓN Y EL RECHAZO
}

\author{
Jon Garay Belategui - Universidad de Deusto \\ Rubén Esteban LÓPEZ PÉREZ - Universidad de León
}

\begin{abstract}
RESUMEN: El presente trabajo se centra en el análisis del concepto de extranjero en el Señorío de Vizcaya y en la villa de Bilbao durante el siglo XVIII y principios del XIX. Así, nos interesa en primer lugar conocer la legislación y límites existentes a la venida de foráneos y el modo en el que éstas disposiciones se aplicaban. Una vez vistos algunos casos concretos de forasteros que llegaron al Señorío y sus motivaciones abordaremos el análisis de la acogida que tuvieron los inmigrantes por parte de la población y de las autoridades locales.
\end{abstract}

PALABRAS CLAVE: extranjeros, limpieza de sangre, inmigración, fuero de Vizcaya, comercio, Vizcaya, Bilbao, xenofobia, siglos XVIII y XIX.

ABSTRACT: This essay deals with the fact of being a foreigner in Vizcaya and the village of Bilbao during the $18^{\text {th }}$ and early $19^{\text {th }}$ centuries. First of all we are interested in knowing the laws and local limits against the arrival of these foreign people, and the way they were put into effect. After having analysed a few examples of foreigners who came to Vizcaya and their motivations, we will study the reception the immigrant people had by the population of the city and the local authority.

KEYWORDS: foreigners, blood cleansing, immigration, Vizcaya's ancient laws, trade, Vizcaya, Bilbao, xenophobia, $18^{\text {th }}$ and $19^{\text {th }}$ centuries.

En el presente trabajo partiremos del estudio de las limitaciones y exigencias legales, fundamentadas en el Fuero Nuevo vizcaíno, impuestas hacia los extranjeros (entiéndase aquí a cualquiera no nacido en Vizcaya) a la hora de acudir al Señorío en general y a la villa de Bilbao en particular a finales del Antiguo régimen. A continuación analizaremos algunos casos específicos de 
extrapeninsulares ${ }^{1}$ o "extranjeros integrales", en palabras de Domínguez Ortiz ${ }^{2}$ de notable importancia vinculados como no podía ser de otro modo a la actividad comercial de la villa ${ }^{3}$, caso de los franceses Luis Violet, Beltrán Douvat y la familia Saint Aulary; las familias irlandesas de los Killy Kelly y Mac Mahon o el caso de la familia Goosens, de origen holandés. Finalmente y como conclusión pasaremos a preguntarnos por la acogida que tuvieron estas gentes entre los naturales, tanto en lo que respecta a las clases populares como en lo referente a su recibimiento por parte de las autoridades locales.

En cuanto a la estructura del trabajo, hemos optado por restringir nuestro análisis a cuatro momentos específicos de alto interés en relación con la política nacional e internacional de la época. Así, partiremos en primer lugar del periodo que abarca los años de 1715 a 1735, el cual desde el punto de vista político viene marcado por el final de la Guerra de Sucesión, de la que salió ganadora la casa de Borbón y cuya estrategia centralizadora quedó puesta de manifiesto en el Señorío con los incidentes de $1717^{4}$. La segunda de las etapas escogidas se sitúa entre los años que van de 1755 a 1770, momento en el que el foco de interés de la política

${ }^{1}$ Quienes, frente a los inmigrantes hispanos (en general miembros de clases populares con posibilidades económicas y perspectivas sociales limitadas), solían pertenecer a nobles familias de hidalgos, con evidentes recursos económicos y una vocación claramente comercial. Ciertamente, esta afirmación debe matizarse, pues durante la Revolución francesa como veremos, acudirán al Señorío muchos pobres e indigentes, y gentes, en general, con pocas posibilidades de medrar en el escalafón social del Antiguo Régimen.

2 Domínguez OrTIZ, A.(1960). Los extranjeros en la vida española durante el siglo XVII y otros artículos. Madrid: C.S.I.C., pp. 67-75. Este autor distingue en primer lugar los "extranjeros peninsulares", lo que venía a significar por ejemplo que los naturales de la Corona de Aragón eran extranjeros en la de Castilla y viceversa; aunque ya en el siglo XVIII, las consecuencias de estas arcaicas disposiciones se hallaban atenuadas o habían desaparecido excepto a efectos fiscales, que aún seguían conservando plena vigencia. En un segundo grupo englobaríamos a los extranjeros de otros "países" de la Corona, quienes lo eran únicamente en Castilla y Aragón, pero en la práctica gozaban de un trato de favor por parte de las autoridades y organismos públicos. Finalmente, hablaríamos de los "extranjeros integrales", aunque en este apartado había sensibles diferencias a tenor de los países de procedencia, según estuvieran considerados como amigos o enemigos, católicos o infieles.

${ }^{3}$ Efectivamente, los extranjeros más notables se dedicaban especialmente a las actividades mercantiles, lo que constituía en la mayoría de los casos las razones de su presencia en el Señorío; bien como miembros avecindados, en su nombre o como poderhabientes de compañías extranjeras; bien como mercaderes eventuales: capitanes de navíos, marineros,... cuyo propósito, además de transportar los cargamentos remitidos podía estar en relación, según la coyuntura histórica, con el establecimiento de protestas de mar, averías o quejas de corso, evidenciables especialmente a fines del XVIII.

${ }^{4}$ La Real Instrucción del 31 de agosto de 1717 ordenaba a todas las aduanas del reino que se situaran en el litoral, medida cuyas consecuencias analizaremos en el capítulo 3 del presente trabajo. 
internacional se centra en la Guerra de los Siete Años. El enfrentamiento se saldará con clara ventaja para Inglaterra, ya que por la paz de Hubertsburg de 1763 Francia renunció a Canadá, quedando así definitivamente confirmado el dominio del mar a su favor. El tercer marco temporal comprende los últimos quince años del siglo XVIII, marcados indudablemente por el proceso revolucionario francés, que como podremos ver, tuvo sus repercusiones en el Señorío. El último período, que coincide con los años de la Guerra de Independencia, puede ser visto como la culminación de los procesos anteriores, esto es, de rechazo de los naturales hacia los extranjeros y especial animadversión hacia el francés.

Podemos adelantar ya que fueron los propios extranjeros los que dominaron la actividad comercial, con especial intensidad desde la creación del Consulado bilbaíno en el siglo XVI ${ }^{5}$. El mecanismo más corriente para desbancar a éstos fue el de la exigencia foral de avecindamiento en virtud de la cual los extranjeros residentes, supuesto que tuvieran el propósito de establecerse; estaban obligados a cumplimentar una serie de formalidades, muchas veces costosas; pruebas que una vez aportadas permitían acceder al conjunto de exenciones, privilegios y libertades que, fundamentadas en el Fuero y otros documentos de diverso rango, gozaban los naturales. A pesar de todo, la mayoría no solía cumplir los requisitos con lo que en teoría podían ser automáticamente expulsados.

\section{LAS DISPOSICIONES LEGALES DEL SEÑORÍO: EL FUERO Y LAS EXIGENCIAS HACIA LOS EXTRANJEROS.}

El concepto de Fuero en el caso de Vizcaya bascula entre dos sentidos distintos. Por un lado, no era más que una norma escrita de los usos y costumbres observados desde tiempo inmemorial, los cuales, en un determinado momento, se van a reconocer como Ley. Es decir, se trataría de la institucionalización jurídica de unos hábitos ya arraigados. Por otro lado, eran también un catálogo de derechos, normas y privilegios concedidos por un determinada autoridad política, ya sea el rey, el señor o un jefe militar, que no estaban enraizados en la tradición local, pero que

\footnotetext{
${ }^{5}$ Durante el resto de la Modernidad, la principal ocupación de los extranjeros continuó siendo la comercial, particularmente la que vinculaba a Bilbao con la exportación de lanas hacia el norte del continente, aunque su tráfico portuario resultó en términos globales regresivo con la excepción de los fructíferos años que van desde 1660 a 1671, según explica el profesor Aingeru Zabala, período en el que los naturales de la Villa trataron de alcanzar el protagonismo local frente a los foráneos. ZABALA Uriarte, A. (1994). Mundo urbano y actividad mercantil en Bilbao. 1700-1810. Bilbao: Biblioteca de Historia del Pueblo Vasco, Bilbao Bizkaia Kutxa, pp. 36-43.
} 
servían de modelo para la organización social y económica de las poblaciones que los recibían ${ }^{6}$.

Las leyes del Fuero Nuevo de Vizcaya (redactado en 1526 frente al denominado Fuero Viejo de 1452) que hacen explícita referencia a los no-aforados y a los extranjeros están contenidas en el primero de sus treinta y seis capítulos. Así la Ley número XIII, establece que en Vizcaya no podían avecindarse los que fueran de linaje de judíos y moros y cómo los que vinieren habían de dar información de su genealogía en el plazo de sesenta días, ya que todos los vizcaínos eran hombres hijosdalgo de noble alcurnia y limpia sangre. Además, tenían de sus Altezas merced y provisión real en relación a que ni los convertidos de linaje de judíos y moros ni sus descendientes pudieran vivir ni morar en Vizcaya ${ }^{7}$. La Ley XIV, continuación de la anterior, dispone que todos los que se hubieran avecindado en Vizcaya y fueran a su vez descendientes de judíos, moros o de recién convertidos dentro de los seis meses siguientes de la publicación de la carta, se debían marchar de los dichos lugares y sus términos, y que desde entonces en adelante no se pudieran ir a avecindar y morar a ninguno de ellos bajo la pena de poder perder sus bienes y de una importante contribución económica ${ }^{8}$. La última de las leyes que aquí nos concierne, la XV, continua la argumentación de la sobrescrita, estableciendo que aun cuando algunos de los nuevamente convertidos alegaren la posesión de alguna cédula o merced del Rey, ésta fuera "obedecida y no cumplida",

Respecto al procedimiento de un proceso cuyo objetivo era demostrar una genealogía limpia de toda mácula, se pueden establecer una serie de características. En primer lugar, se trata de una práctica de origen romano-canónico, la cual fue adoptada, desarrollada y empleada por la cultura jurídica del "ius commune". Un segundo aspecto es que estamos ante un procedimiento abreviado, puesto que se

${ }^{6}$ Esta distinción está extraída de la obra de GARCÍA De CoRTÁzAR, F. y LoREnZo EsPinOSA, J. M. (1988). Historia del País Vasco. San Sebastián: Txertoa, p. 68. Es importante señalar que la posesión o disfrute de un régimen foral no era exclusivo del País Vasco. Por el contrario, de acuerdo con la evolución general del Estado, casi todas las provincias, pueblos, ciudades y villas peninsulares tenían el suyo, siendo muy semejantes entre sí. Lo que caracteriza al régimen foral vasco es su pervivencia en el tiempo, ya que, como es sabido, éste no fue abolidos hasta 1876.

${ }^{7}$ VVAA. (1977). El Fuero. Privilegios, franquezas y libertades del muy noble y muy leal señorío de Vizcaya. Bilbao: Diputación Provincial de Vizcaya, 1977. Fuero Nuevo, Capítulo I, Ley XIII: "Que en Vizcaya no se avecinden los que fueren de linaje de judíos, e moros; e cómo los que vinieren an de dar información de su linaje".

${ }^{8}$ Fuero Nuevo, Capítulo I, Ley XIV. Fechada en Burgos el 8 de septiembre de 1511.

${ }^{9}$ Fuero Nuevo, Capítulo I, Ley XV. 
suprimen las formalidades y fases de un proceso ordinario, que incluiría, entre otras, la exposición de pruebas contrastadas, la participación de abogados y la presentación de alegaciones. En tercer lugar, el objetivo es, como ya hemos señalado, probar conforme a lo "notorio, pública voz y fama" si el informado y su ascendencia bilateral son o no limpios de sangre y si el honor del individuo es equiparable públicamente al de la institución que, de exigir esta demostración, lo iba a aceptar. Para ello, no se suele recurrir a pruebas materiales, siendo la mayor fuerza probatoria o desaprobatoria la pública voz y fama, es decir, la opinión que emitan los testigos. Por último, hay que decir que la validez de lo demostrado se limitaba a la institución a la que el interesado había ofrecido la información, pero si éste pretendía acceder a otra institución, debía nuevamente demostrar su honor y calidades a través del correspondiente informe ${ }^{10}$.

Como ejemplo práctico hemos elegido una caso que afectó a un individuo de procedencia irlandesa llamado Patricio Mac Mahon ${ }^{11}$. La razón de la elección del mismo es el especial status de que gozaban los irlandeses, gracias a una Real Cédula expedida por Carlos II $^{12}$. Procedente de la ciudad de Cork, éste presenta en 1767, con el objeto de poder avecindarse y de acuerdo a la normativa descrita en el apartado anterior, información sobre su filiación, ascendencia y limpieza de sangre (amén de los testigos necesarios para la validación de su testimonio) ante Don Marcos Manuel de Aguirre, síndico procurador general del Señorío de Vizcaya, y Don Joaquín de Elordui, síndico procurador general de la villa de Bilbao.

El siguiente paso del proceso es la presentación de las preguntas que serán realizadas a los testigos presentados por el interesado. Por lo general, suelen ser alrededor de diez, si bien en este caso se reducen a siete. Concretamente, la primera de ellas hace alusión al conocimiento de las partes y noticias de la presente causa y de los padres y ascendientes del dicho Patricio; la segunda, se interesa por la ascendencia paterna (su abuelo fue Terencio Mac Mahon, muerto a los 107 años, y

10 TABOAda Roca, M. (1991). Las probanzas de hidalguía antes y después de 1836. Madrid. Ediciones Hidalguía., pp. 24-32.

11 Archivo Foral de Vizcaya (en adelante A.F.V.), Sección Bilbao Antigua, fondo municipal, legajo 0407/001/002, pieza 453, registro 43 de genealogías

${ }^{12}$ Esta condición queda reflejada en la Real Cédula del 3 de febrero de 1668, por la cual los irlandeses católicos tendrían acceso a las mismas prerrogativas e inmunidades que los naturales; cédula que fue revalidada en 1681 y posteriormente ampliada por Felipe V en 1701 y 1724. A esta legislación hay que añadir la Real Provisión del 5 de mayo de 1725, por la que se hacía innecesario el envío de persona alguna al Reino de Irlanda para realizar la comprobación de los documentos de limpieza de sangre presentados por irlandeses con objeto de la posterior obtención de las ventajas ya descritas. 
su abuela Margarita Uleade, fallecida a los 96 años en 1756, al igual que su marido. De su unión, nació Diego Mac Mahon, padre de Patricio); la tercera se refiere a la relación conyugal entre Diego Mac Mahon y Eleonora Maccurtain, progenitores de Patricio; la cuarta, se interesa por la familia de su madre, fruto del matrimonio de Cornelio Maccuntain y Juana Juin; la quinta, inquiere acerca del conocimiento que tienen sobre si tanto Patricio como sus ascendientes "han sido y es christiano viejo limpio y de limpia sangre apartado de toda mala raza de moros, judios nuevamente convertidos y penitenciados por la Santa Inquisición, noble hijodalgo notorio de sangre (...) y en esta posesion fama y reputación han estado y estan todos los ascendientes y descendientes del dicho Don Patricio de diez, veinte, treinta, cuarenta, sesenta, ciento y mas años que memoria de ombres no es contrario y lo saven los testigos por asi haverlos visto ser y pasar en el tiempo de su acorda y haverlo oydo decir a sus mayores y mas ancianos y éstos de los suios (...); la sexta, hace referencia a si conocen las Reales Cédulas que otorgan a los irlandeses una situación especial; y la séptima y última es una confirmación de si saben que todo lo anterior es cierto.

Una vez citados e interrogados los testigos, en este caso seis, el representante de Patricio, de nombre Francisco de Nanclares, pide una copia y la correspondiente certificación de las Reales Cédulas, petición que obtiene. Como paso previo a la sentencia, el apoderado solicita que se declare a su representado limpio de sangre e inmaculado, lo que significaría obtener el permiso necesario para el ansiado avecindamiento. Efectivamente, la sentencia confirmará la verosimilitud de su petición ${ }^{13}$.

En conclusión, podemos decir que el Fuero estipula claramente que todo extranjero (aquel que ha nacido fuera de las fronteras vizcaínas), debía avecindarse previamente, en el plazo de sesenta días, para el disfrute de cualquier tipo de oficios públicos y honoríficos "que se dan y reparten en esta Villa y en este

13 “(...) declaramos al dicho Don Patricio Mac Mahon, por si, sus Padres, Abuelos, paternos, y maternos y demas ascendientes de una y otra linea, por Christiano Viejo Católico Apostolico Romano limpio de toda mala raza de Judios, moros, herejes, y convertidos nuevamente a nuestra Santa Fee Católica, ni penitenciados por el Tribunal de la Inquisición, y de otra reprobada secta Nobles hijos Dalgo notorio de sangre, y en su consecuencia mandamos que al dicho Don Patricio Mac Mahon le haian y tengan por tal admitiéndole a la vecindad de esta Villa y demas Anteiglesias Villas, Ciudad, Encartaciones, y merindad de Durango, de este dicho señorio donde quisiese, y lo pidiere, y a los oficios publicos, y honorificos que se dan, reparten y comunican a los Nobles hijos dalgo dándole los demas honores, exempciones franquezas, prerrogativas, y libertades que deven gozar personas de higuales circunstancias, y de todo para su reguardo se le den y entreguen al dicho Don Patricio los traslados que pidiere signados, y en publica forma sellados con el sello mayor deeste nominado Señorio (...)". 
Señorio”, según apuntan las fuentes. No obstante, únicamente podrían gozar de esta condición aquellos que recibiesen del síndico procurador general el "sello mayor"; es decir, quienes además de atestiguar su limpieza de sangre, aportasen pruebas fehacientes; (normalmente mediante la compulsa de las partidas bautismales, actas de casados y difuntos,... de sus lugares de origen; así como el pertinente interrogatorio más o menos exhaustivo de testigos), de sus condiciones nobiliarias, como hijosdalgo. Si por el contrario, sólo lograban demostrar su limpieza de sangre, recibirían un traslado de su solicitud signado con el "sello menor", mediante el cual quedaban admitidos a la vecindad, pero no al disfrute de cargos públicos.

\section{CASOS MÁS DESTACADOS DE EXTRANJEROS.}

Tradicionalmente, la historiografía ha dicho que tras la Guerra de Sucesión, los bilbaínos llegaron a arrinconar en el plano comercial a los foráneos, afirmación que puede resultar evidente a primera vista. No obstante, debemos replantearnos la cuestión, ante la presencia de casos tan notorios como los que más adelante citaremos. Lo primero que llama la atención es la continuidad de algunos de ellos, como la familia Goosens; familia que aunque no alcanzó grandes cotas de comercialización, ya había llegado a la Villa a fines del siglo XVII ${ }^{14}$. En segundo lugar, destaca el número, puesto que ronda la treintena de casas comerciales, es decir, excesivas en relación al comercio total de Bilbao. Por otra parte, es cierto que a partir de 1785, las casas fueron desapareciendo y salvo en escasas ocasiones, no se produce una sustitución de las familias foráneas.

No hay que olvidar que la condición de extranjero no podía permanecer de forma indefinida. En la primera generación, aun con avecindamiento, se carecía de todo derecho. La segunda generación gozaba ya de derecho al voto, pero no podían ser elegidos; y la tercera, poseía plenos derechos en caso de vecindad ininterrumpida. Así, hacia fines del siglo XVII, algunos extranjeros ya no eran considerados como tales por los bilbaínos, llegando a ocupar cargos en el Consulado o en el Gobierno de la Villa, caso de los citados Goosens. A lo largo del Setecientos, la mayoría de los extranjeros estarán dedicados al comercio, entre ellos los más significativos serán irlandeses, franceses y de los Países Bajos. Los primeros procedían generalmente de las inmediaciones de Dublín (Antonio Linch, Domingo Killi Kelly y Patricio Mac Mahon); los flamencos, de Amberes (Juan Enrique Goosens); y los franceses, de Bayona y de sus alrededores (Enrique y Juan

\footnotetext{
${ }^{14}$ Esta referencia la recogemos de Zabala Uriarte, A. (1994). Mundo urbano..., Op. cit., p. 476, ya que nuestra investigación se halla limitada al siglo XVIII y principios del S. XIX.
} 
de Saint Aulary, Beltrán Dovat...). Se daba en todos ellos, o al menos en su mayor parte, una cierta tendencia al emparentamiento "endogámico". Destaca el caso de los Linch, los Killi Kelly y los Moroni, socios y parientes. En concreto, en 1754, María Killi Kelly, hija de Domingo, se casó con Juan Moroni; en 1764, un hermano de María, Bernardo Pablo y Juan Moroni fundaron una asociación comercial, que renuevan más adelante... ${ }^{15}$.

Otro aspecto es que, salvo ciertas familias, entre ellas los Goosens, la mayoría retornaron a sus países de origen. Sin embargo, aunque los comerciantes foráneos tenían una conciencia de grupo ampliamente demostrada, en la cual influyeron decisivamente los intereses económicos, especialmente los matrimonios, se dio en los que no tenían intención de marcharse, un proceso de integración social en Bilbao. Este trato mejoró extraordinariamente en las segundas generaciones y se vio especialmente impulsado a fines de siglo, cuando las relaciones fueron más abiertas y existieron menos trabas jurídicas ${ }^{16}$.

\section{Saint Aulary:}

El miembro más destacado de esta familia fue Enrique, bautizado en Bayona en agosto de 1687 y que presentó su genealogía con el fin de avecindarse en Bilbao en 1714 (en 1733, hará lo propio su hermano menor Juan). Enrique fue aceptado a residir en la Villa y en el Señorío, pudiendo gozar de sus oficios honoríficos; y en una fecha tan temprana como 1716, aparece como poderhabiente en Bilbao de un tal Bernando Ditorronde, vecino y mercader de la ciudad de Burdeos, residente en Bilbao.

Un año después, en 1717, reclamó junto a comerciantes de la talla de "Juan Van Duffel y Compañía" y otros mercaderes nativos contra el alcalde y juez ordinario de Portugalete, quien insistía en impedir la salida del navío francés "Nuestra Señora de Begoña" hacia Bayona, cargado por los demandantes con diversas mercaderías, habiendo obtenido ya todas las licencias necesarias.

Su actividad no cesó durante toda la primera mitad del siglo XVIII. A partir de entonces, el protagonismo pasó a Tomás de Saint Aulary (no sabemos exactamente su parentesco, pero pensamos que posiblemente sea su hijo), quien, en 1758, actúa como poderhabiente de una compañía de Amsterdam en un caso de impago por parte de un lugareño. En 1759, vio cómo una carga de bacalao y grasa procedente

15 Es muy complejo describir todos los lazos y actividades de esta familia, por lo que nos conformaremos con una somera visión de los aspectos fundamentales.

${ }^{16}$ Zabala Uriarte, A. (1994). Mundo urbano..., Op. cit., pp. 376-423. 
de Terranova caía en manos del corso francés, presentando por ello unos autos ante el Consulado de Bilbao. Su labor como poderhabiente continua en 1763, cuando representó a un tal León Deschamps, comerciante de Bayona, contra unos bilbaínos sobre el pago del seguro de un navío.

De aquí en adelante, nuestros datos resultan confusos: en 1769, la viuda de Saint Aulary (suponemos que la de Tomás) nombró peritos para que tasasen averías en un barco, es decir, parece tomar las riendas del negocio de su ¿marido?, algo que no deja de ser extraño a tenor de nuestros datos para aquel momento. Además, en 1785 aparece de nuevo un Enrique de Saint Aulary, (podemos pensar que se trate de su nieto puesto que el primero contaría con 98 años), quien promueve unos autos para que se le paguen unos reales procedentes de salarios y servicios prestados como mayordomo factor de la casa comercial oriunda de Bilbao.

Por si esto fuera poco y la situación no se hubiera complicado lo suficiente, en 1790 está documentada la presencia nuevamente de otro Tomás de Saint Aulary, quien recibe un cargamento de sal procedente de Vannes (Francia) y cuyo capitán se vio obligado a declarar sobre su no contagio de peste. Lo que es claro es que su actividad decae hasta tal punto que no tenemos más noticias de ellos en el periodo estudiado $^{17}$.

\section{Killi Kelly:}

El apellido Killi Kelly aparece por vez primera en Vizcaya en junio de 1733, cuando Domingo, bautizado en 1701, presentó su genealogía para avecindarse. Esta familia, según datos del archivo, provendría de Dathie Fiathragb, supuesto monarca de Irlanda entre el año 405 y el 428 d.C. Al parecer, el linaje disponía de escudo de armas: "dos leones en campo verde soportando un castillo con tres torrecillas doradas entre tres medias lunas... y el letrero FORTIS ET STABILIS". Además, eran propietarios de un torre en Lidicán, su lugar de origen, sito en la provincia de Conacia, en el reino de Irlanda.

A tenor de nuestros datos, en 1760 aparece integrado en la sociedad "Linch, Killi Kelly" en unos autos sobre el pago de una avería. En un pleito de 1765, se

${ }^{17}$ Para seguir de esta familia, los recursos de archivo (A.F.V.) empleados en orden de aparición han sido los siguientes: Sección Bilbao Antigua, fondo municipal, , leg. 0395 / 001, pieza 376, registro 31 de genealogías. Sobre su actuación como poderhabiente en 1716, Sección Judicial, Corregimiento, legajo 0225 / 023; en 1717, leg. 1147 / 008; respecto al "primer" Tomás de Saint Aulary, en 1758, leg. 0325 / 024; en 1759, leg. 0738 / 021; y en 1763, 1423 / 029. En relación al caso de la viuda, leg. 2058 / 026. La aparición de 1785, leg. 1500 / 016, y la de 1790, leg. 2173 / 039. 
habla ya de los señores "Linch, Killi Kelly y Moroni", comerciantes de Bilbao, actuando como apoderados de una sociedad londinense contra un comerciante local sobre impago de una letra de cambio (téngase en cuenta que, como hemos señalado más arriba, estas tres familias habían emparentado entre ellas, constituyéndose en sociedad en 1764). Esta compañía se mantendrá activa hasta fines del XVIII, como apoderados de compañías extranjeras; en 1767, reciben unos autos que les impelen a pagar 1.716 reales de vellón procedentes de los portes de 104 arrobas de bacalao; en 1785, testimoniamos el naufragio de un bergantín en el puerto de Plencia, procedente de Gijón, y que llevaba a su nombre una carga de avellanas, cueros, carbón, habichuelas, nueces y unos cajones de Talavera. Por último hemos logrado atestiguar el momento en el que la sociedad se disuelve, hecho que ocurre a fines de 1797. Mediante una escritura de poder, Bernardo Pablo Linch Killi Kelly, valiéndose de terceras personas, abonó 24.000 reales de vellón, el resto de una cuantía mayor que debía a Juan Moroni; cantidad perteneciente a la compañía que ambos tuvieron $^{18}$.

\section{Luis Violet:}

Luis Violet (o Viollete) era originario de la villa de Saumur, en el reino de Francia, nacido poco después del matrimonio de sus padres, Claudio Violet y Cathalina Herbi, en septiembre de 1710. Presentó su genealogía el 21 de marzo de 1750 , siendo autorizado a avecindarse y a poder acceder a los oficios honoríficos.

La primera nota que tenemos de él a nivel judicial data de 1755, en unos autos promovidos por un tal Herman Van de Pol, vecino de Amsterdam, por el pago de 10.427 reales, una suma bastante considerable, pues era el resto de una cuenta de lana, tejidos y fletes que éste debía. Seis años más tarde, en 1761, intenta unos pleitos contra otro famoso extranjero comerciante de la Villa, Juan Enrique Goosens, acerca del pago de una cantidad similar a la anterior, 10.224 reales y 18 maravedíes, derivada del pleito que ambos seguían en Londres en reclamación del casco, aparejos y carga del navío francés "Gran San Luis", apresado por los ingleses ${ }^{19}$.

18 Sobre la genealogía de Domingo Killi Kelly, aparece en A.F.V., Sección Bilbao Antigua, fondo municipal, , leg. 398 / 001, registro 34 de genealogías. Sobre la sociedad "Linch Killi Kelly, véase en el mismo archivo, Sección Judicial, Corregimiento, leg. 0781 / 002; acerca de la compañía "Linch, Killi Kelly y Moroni”, legs. 0062 / 035, 2145 / 014 , 0994 / 008 y 0558 / 009. La escritura de poder que habla de su separación se encuentra en leg. $0291 / 013$.

19 Téngase en cuenta que este hecho se produce en el marco de la Guerra de los Siete Años, en la que Francia e Inglaterra eran enemigas. 
Dos casos terminarán por llevar a la quiebra a Luis en 1765, a saber: el 19 de junio del citado año, Violet presentó un auto reclamando una cantidad no especificada de reales a un comerciante local para pagar la arboladura y tablación de dos embarcaciones; y el 22 de octubre, la sociedad "Goosens y Compañía", como poderhabientes de un comerciante de Amsterdam, le reclamaron el pago de 3.725 ducados, 6 sueldos y 11 dineros, procedentes de letras de cambio. Estas deudas no pudieron ser positivamente resueltas, con lo que el 19 de noviembre, nos encontramos en las fuentes con dos piezas de los autos de su quiebra ${ }^{20}$.

\section{Goosens:}

Las primeras noticias que tenemos de un miembro de esta familia datan de 1761, y se refieren a Juan Enrique, originario de Amberes y bautizado en 1713, contra el que Luis Violet, como acabamos de ver, pleiteó para que le restituyese la cantidad arriba recogida. En 1765, las tornas se invierten y es en esta ocasión "Goosens y Compañía" quien hace lo propio. Ese mismo año, aparece documentada la presentación de genealogía tanto de Enrique como de su hermano mayor, bautizado en 1702, Pedro Francisco, el cual llegará a ser ministro de "capa y espada" de Hacienda en 1770 por Real Cédula de Carlos III $^{21}$.

Las actividades de los Goosens en la segunda mitad del siglo XVIII no serán de gran importancia, sufriendo desde la década de los Setenta un progresivo retroceso. Las acciones comerciales se centrarán básicamente en productos menores como la lana. Como ejemplo de esto, tenemos las diligencias promovidas por "Goosens e hijo" en 1799, para que se procediera a la tasación de una partida de lana, remitida por un tal Alejandro González Lodidana, vecino de Vitoria. A partir de aquí no disponemos de más datos de las vicisitudes de los Goosens ${ }^{22}$.

${ }^{20}$ La petición de hidalguía y nobleza de sangre de LuisViolet la encontramos en A.F.V., Sección Bilbao Antigua, fondo municipal, , leg. 404 / 001, pieza 434, registro 40 de genealogías. En el mismo archivo, el aspecto judicial en Sección Judicial, Corregimiento leg. 1484 / 009; 0781 / 005; 0094 / 007; y la quiebra en leg. $2080 / 002$.

${ }^{21}$ A.F.V., Sección Bilbao Antigua, fondo municipal, leg. 0407/001/002, pieza 452, registro 43 de genealogías.

${ }^{22}$ Los datos genealógicos proceden de A.F.V., Sección Bilbao Antigua, fondo municipal, , leg. 0407 / 001 / 002, pieza 472, registro 43 de genealogías. Los dos pleitos contra Luis Violet están en corregimiento, leg. 0781 / 005 y 0094 / 007. Las diligencias de "Goosens e hijo" en 1799 están en leg. $2121 / 012$. 


\section{Mac Mahon:}

En lo que respecta a la familia de los Mac Mahon, observamos en fecha de 1756, unos autos sobre la quiebra y concurso de un tal Terencio, el cual, no obstante, va a aparecer en 1763 como corredor de navíos, promoviendo unos autos para que se entreguen a sus respectivos dueños las mercancías averiadas que se salvaron del varamento de un navío que procedía de Amsterdam, en los arenales de Algorta. Es asimismo destacable su actividad en 1764, cuando realiza diligencias con el fin de que se nombren peritos que tasen las averías de una carga de escarlatina, sempiterna y queso, remitido desde Exon (Inglaterra).

En 1767, otro miembro de la familia, Patricio Mac Mahon, procedente de la ciudad de Cork, en el reino de Irlanda, lleva a cabo la presentación de su nobleza y limpieza en sangre, por la cual será aceptado a la vecindad de la Villa de Bilbao (cuyo caso fue expuesto en el punto 1). Al año siguiente, Diego Mac Mahon, (pensamos que se trata del hermano de Patricio) hará lo propio. A partir de entonces, ambos se repartirán el total de las acciones judiciales puestas en práctica por dicha familia hasta finales de siglo. En 1769, Patricio pleitea contra un comerciante bilbaíno como consecuencia de la paga de 1581 reales, derivados de una cuenta de fletes ${ }^{23}$. Diego Mac Mahon adquirió protagonismo desde 1785, momento en el que promovió unos autos contra un vecino de Bilbao sobre el pago de fletes. Al año siguiente, demandó al vecino de la Villa, José Antonio de Lorea, por un pago de 2.434 reales y 21 maravedíes de vellón que le debía por nuevos fletes; el mismo individuo sería nuevamente demandado un año después. Seguirá pleiteando por esta misma razón en 1788 contra Joaquín de Vidal, y en 1791, contra José Antonio de Urraza, ambos naturales de Bilbao. A partir de aquí, carecemos de más referencias respecto a esta familia ${ }^{24}$.

\section{Beltrán Douvat}

Douvat había nacido en Cibourne (Francia) el 18 de diciembre de 1742, en el seno de una familia noble y de posición económica desahogada. Muy joven, juntamente con su hermano menor Claudio, marchó a Bayona para iniciarse en los negocios mercantiles; y después, con la práctica adquirida, ambos hermanos se

${ }^{23}$ Un flete es el precio del alquiler de una nave o de otro medio de transporte. También se entiende por ello a la carga que se transporta tanto por mar como por tierra.

${ }^{24}$ La petición de reconocimiento de nobleza e hidalguía de Patricio Mac Mahon ha sido estudiada en el punto 1. Sobre los casos de Terencio Mac Mahon, véase A.F.V., Sección Antigua, Corregimiento, leg. 0445 / 013 y 0553 / 038. El auto de Patricio de 1769 figura en legs. 1573 / 012; y los de Diego, en legs. 2196 / 015; 2059 / 018; 2133 / 003; 2094/027 y $2151 / 003$. 
instalarían en Bilbao en 1763, pero aquí no solicitaron el avecindamiento, ni quisieron someterse a las pruebas de limpieza de sangre e hidalguía exigidas por el Fuero.

En 1784, casó con María Power y Echávarri, hija del poderoso comerciante Felipe de Power. Beltrán dedicó su actividad a importantes negocios de importación y exportación con la Europa del norte y la América inglesa, actuando como banquero en sociedad con los también franceses señores Planté y Lavat. Así, en 1785, promovió unas diligencias para que se tasase una carga de olona remitida desde San Petersburgo; y en 1786, redactó el expediente de naufragio de un bergantín que le traía bacalao desde San Juan de Terranova.

En 1789, en la cumbre de su poder y prestigio, compró a la familia de los marqueses de Santa Cruz, el título de marqués de Bayona, que cambiaría por el de marqués de la Colonilla. Tras sucumbir a la presión de las autoridades, que alegaron que era agente de la Revolución, fue encarcelado en 1792, para posteriormente ser desterrado. Los últimos años de su vida los pasó entre Burgos y Burdeos, donde murió en 1816. Los socios del marqués, señores Lavat y Planté, no sufrieron perjuicio alguno ni en sus personas ni en sus negocios, pero su declive iba a ser inminente. De esta manera, la sociedad "Lavat e hijo" redactó unas diligencias en 1810 para que unos peritos tasaran una fragata con el fin de venderla en público remate. Efectivamente, el 29 de octubre de 1811, Pedro y Eugenio de Lavat, padre e hijo, declararon extinguida la sociedad comercial que hasta entonces habían constituido ${ }^{25}$.

\section{LA ACOGIDA DE LA POBLACIÓN Y LA POSTURA DE LAS AUTORIDADES: UNA VISIÓN DESDE EL RECURSO A LA JUSTICIA.}

Para entender la actitud hacia los extranjeros por parte de la población local y de las autoridades en general, centraremos nuestra atención en el apartado judicial. Tendremos en cuenta pues los pleitos, autos y diversos recursos a la justicia del Señorío que se llevaron a cabo, con el fin de acercarnos a una perspectiva de las mentalidades y de la vida cotidiana lo más fidedigna posible, atendiendo a los cuatro períodos comentados en la Introducción.

${ }^{25}$ Para este caso, nos hemos apoyado en Feijoó CAStillo, P. (1989). "Guerra de la Convención y Guerra de la Independencia”, en VVAA. Vizcaya. 1789-1814, Bilbao: Diputación Foral de Vizcaya, pp. 257 y ss. y en A.F.V., Sección Judicial, Corregimiento, leg. 2093 / 002; 1151 / 043; en relación a "Labat e hijo", 0961 / 012 y 1292 / 013. 


\section{5-1735:}

El hecho más importante para el Señorío en este primer momento, fue la Real Instrucción del 31 de agosto de 1717, que ordenaba a todas las aduanas del reino que se situaran en el litoral, medida que afectó de modo muy diferente a los diferentes grupos sociales. La nobleza rural no podía ver con demasiados malos ojos una situación que en principio suponía un duro golpe a sus rivales más directos, los comerciantes bilbaínos. Sin embargo, entre el grupo de comerciantes no había una visión homogénea del traslado de las aduanas. A los grandes comerciantes, exportadores de hierro y reexportadores de lana, ésta les afectaría mínimamente. Por el contrario, sí resultaban afectados, y profundamente, los comerciantes de productos coloniales y los importadores de artículos de consumo; éstos, habían de pagar un arancel que antes no pagaban, además de vigilarse el contrabando con mayor fuerza. En este sentido, los miembros del colectivo mercantil, entre ellos los extranjeros, recurrieron a toda clase de mecanismos para neutralizar la medida. La revuelta duró poco, pero sus efectos fueron amplios: fue fructífera, pues poco después se concedió el retorno de las aduanas al interior en 1723 sin contrapartida inmediata de libertades forales. Podemos decir por lo tanto que los comerciantes fueron los vencedores del conflicto ${ }^{26}$.

Después de la Guerra de Sucesión, los vizcaínos reanudaron sus ataques contra los comerciantes extranjeros, ya que la mayoría de la contratación mercantil seguía en sus manos; y su presencia dificultaba la obtención de beneficios, no excesivos tras las dificultades derivadas del conflicto. A pesar de todo, los extranjeros seguían acudiendo, constituyendo en torno al $13 \%$ de la población ${ }^{27}$. Ante ello, aumentaron las medidas restrictivas, limitando con las ordenanzas del Consulado de 1725 la plenitud de los derechos a las terceras generaciones en el ejercicio mercantil, medidas que serán recurridas por los foráneos.

Atendiendo a las fuentes, desde 1715 al 35, la utilización de la vía judicial se circunscribe básicamente a las protestas que los foráneos realizan acerca de impagos, tanto entre ellos como con los naturales. Así, de un total de 32 casos analizados, 16 aluden esta cuestión. Por ejemplo, los autos que, el 6 de junio de 1716, el comerciante Enrique de Saint Aulary, del que ya hemos hablado, como poderhabiente de un tal Bernardo Ditorronde, vecino y mercader de la ciudad de Burdeos y residente en la villa de Bilbao, llevó a cabo contra Luis Poncet, también

${ }^{26}$ Zabala Uriarte, A. (1994). Mundo urbano..., Op. cit., pp. 86-89.

${ }^{27}$ Zabala Uriarte, A. (1994). Mundo urbano..., Op. cit., p. 151. 
mercader francés, sobre la paga de dos mil escudos de plata procedentes del valor de una partida de borra de bueyes o vacas ${ }^{28}$.

Por otro lado, es apreciable que el $25 \%$ de los pleitos (ocho), aluden de forma directa o indirecta al empleo de la violencia. En esta línea, se inscribe el caso acaecido el 29 de octubre de 1717, en el que el Corregidor promueve de oficio autos criminales contra unos marineros ingleses por desórdenes públicos y lesiones causadas al bilbaíno Ignacio de Barbachano, a Juan de Ugarriza, alias "Narru", vecino de la anteiglesia de Deusto, y un tal Guillermo, de ignorado apellido, cervecero residente en dicha anteiglesia. Frente a esta agresiva actitud, los locales reaccionaron en ocasiones con acciones que podían incluso concluir con el asesinato del individuo extranjero, tal y como sucedió el 31 de marzo de 1713, cuando Antonio de Macazaga, carpintero y vecino de la anteiglesia de Deusto, y Pedro de Lozano, de la misma vecindad, fueron acusados de la muerte de Eduardo Marks, marinero de Bristol que había venido en el navío inglés "Zafi" 29 .

Otros delitos de menor entidad en este período son los robos y hurtos perpetrados en este momento. Así, el caso del 11 de enero de 1720, momento en el que la Real Justicia presentó unos autos criminales contra Juan Casaulet, natural de Bayona, y contra Juan Francisco Ronville, también francés, por haberse adueñado ilegítimamente de una serie de abalorios ${ }^{30}$.

\section{5-1770}

Dentro del contexto de la guerra de los Siete Años, tal y como señala el profesor Aingeru Zabala, un acontecimiento a destacar será la derrota española en la batalla de Quebec en 1759 ante los franceses, ya que significó el declive del comercio bilbaíno del bacalao con este ámbito ${ }^{31}$. En 1763, se firmó la paz de París y la complementaria de Hubertersburgo, por las que se ponía punto y final a la guerra. Desde entonces al final de la década, la relativa paz interna y una no menos precaria externa caracterizarán la situación del comercio de la Villa. Sin embargo, desde inicios de la década de los cincuenta, se entra en una dinámica positiva para las actividades comerciales. Este aspecto se dejará notar claramente en la abundancia de las iniciativas mercantiles, así como en el aumento de las compañías y del tráfico de productos. Las casas comerciales destacan por su continuidad desde

\footnotetext{
${ }^{28}$ A.F.V., Sección Judicial, Corregimiento, legajo 0225/023.

${ }^{29}$ A.F.V., Sección Judicial, Corregimiento, legajo 0906/003.

${ }^{30}$ A.F.V., Sección Judicial, Corregimiento, legajo 0916/019

${ }^{31}$ Zabala Uriarte, A. (1994). Mundo urbano..., Op. cit., pp..184-185.
} 
1740, como vimos con los franceses Tomás de Saint Aulary o Luis Violet; los irlandeses Patricio y Terencio Mac Mahon y la también irlandesa "Linch, Killy y Kelly" (que hacia 1765 se transforma en "Linch, Killy Kelly y Moroni"), o el flamenco Juan Enrique Goosens.

Precisamente, desde 1765, comienzan las dificultades: ciertos problemas en los puertos americanos que proveían de pescado a Bilbao, al tiempo que un pequeño incidente en las Malvinas hizo temer por una paz que tan difícil resultaba de mantener entre ingleses españoles. El tráfico y negocio conocieron en consecuencia una fuerte recesión. En la Villa, la sensación de desánimo era importante y un observador real dijo al respecto que "está arruinado, no hay tomadores de letras por las continuas quiebras que se experimetan" 32 , por lo que además faltaba numerario en la plaza.

Recurriendo de nuevo a la documentación del fondo judicial, hemos hecho una selección de unos cincuenta casos, de los cuales, como en el periodo anterior, casi el $50 \%$ de los mismos corresponde a impagos. De ellos, el más destacable por su cuantía económica sería el correspondiente a los autos promovidos el 6 de marzo de 1755 por José de Ansoleaga, vecino y comerciante de Bilbao, contra Patricio Dowaal, comerciante irlandés, sobre la paga de 19.225 reales y 14 maravedíes procedentes de una partida de hierro remitida a Miguel Reyly, vecino y del comercio de Dublín ${ }^{33}$.

Tras los pleitos por impagos y de la misma manera que ocurre en el periodo 1715-1735, en torno al 25\% de los casos (12 de 50) hacen referencia a robos y violencia. Merecen ser citados, a modo de ejemplo, los autos criminales promovidos de oficio por la Diputación de Vizcaya el 13 de septiembre de 1759 contra Luis Des Essarts, comerciante francés vecino de Bilbao, sobre injurias y malos tratos a Andrés de Barrenengoa, síndico procurador general del Señorío de Vizcaya. Asimismo, se informa que las injurias se producen en un viaje a Francia realizado por ambos para verificar la genealogía y limpieza de sangre del demandado ${ }^{34}$.

\section{5-1800}

Este periodo resulta de un interés extraordinario puesto que, además de la riqueza documental que presenta para el estudio de las compañías comerciales (la

\footnotetext{
${ }^{32}$ Zabala Uriarte, A. (1994). Mundo urbano..., Op. cit., p. 322

33 A.F.V., Sección Judicial, Corregimiento, leg. 0467 / 015

${ }^{34}$ A.F.V., Sección Judicial, Corregimiento, leg. 0140 / 002.
} 
mayoría de las cuales entra en decadencia), ofrece claras pruebas, sólo comparables a las del periodo posterior, sobre el efecto de los acontecimientos políticos internacionales en la actitud de los lugareños hacia los foráneos, especialmente hacia los franceses.

El principal acontecimiento de este periodo es la Revolución liberal burguesa de 1789, importándonos especialmente lo relacionado con su difusión y acogida en el marco del Señorío de Vizcaya. Con anterioridad a este acontecimiento, el crecimiento demográfico siguió presionando sobre las pocas viviendas disponibles, mientras que las tensiones sociales, hasta entonces más o menos soterradas, se fueron agravando. A las deficiencias estructurales, se suman los males coyunturales; así el bloqueo francés a Inglaterra se traduce en 1790 en un completo hundimiento del comercio bilbaíno. Y por si ello fuera poco, el mar se puso casi impracticable: siguiendo al profesor Zabala, las protestas de $\operatorname{mar}^{35}$ que se recogen en la capital vizcaína ya desde 1765 hasta 1800 , reflejan cómo el número de accidentes va en aumento. En este sentido, 1 de cada 10 navíos que entraron aquel año en el Nervión porfió contra el estado del mar y de las averías ${ }^{36}$ padecidas por su causa ${ }^{37}$.

Entre tanto, los refugiados, clérigos en especial, del país vecino llegaban en cantidades importantes a Bilbao. Durante la guerra, los franceses ocuparon San Sebastián, llegando en 1795 a la capital vizcaína. Este hecho marcó profundamente la vida de la Villa; así, "en aquel mes de julio de 1795, sucedieron demasiadas cosas en Bilbao, como para no dejar huella: la mayor parte de los gobernantes huyeron...pero aquellos que salieron de Bilbao regresaron muy pronto... y regresaron dispuestos a recuperar sus viejas posiciones de dominio; la posguerra

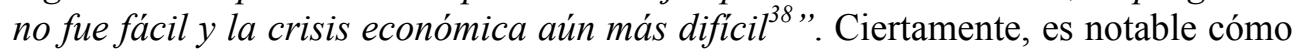
la guerra fortaleció la vieja, aunque no demasiado trascendente xenofobia y facilitó el anhelo de expulsar a poderosos hombres de negocios (extranjeros), cuya

35 Podemos definir una "protesta de mar" como la declaración justificada del que manda un buque, el capitán, con el fin de dejar a salvo su responsabilidad en caso de cualquier accidente fortuito. Su explicación reside en la dificultad que suponía por aquel entonces la realización de viajes de larga distancia y, sobre todo, sus maniobras en zonas de escasa profundidad, cuando el tonelaje de la embarcación era de cierta entidad.

${ }^{36}$ Cuando hablamos de "avería", nos referimos al daño que por cualquier causa, accidental o no, sufre una embarcación o su carga.

${ }^{37}$ Estas últimas ideas las hemos tomado de Zabala Uriarte, A. (1994). Mundo urbano..., Op. cit., pp.. 326-327.

${ }^{38}$ Zabala Uriarte, A. (1994). Mundo urbano..., Op. cit., pp..331 
prosperidad era vista con animadversión en aquellos problemáticos momentos. La expulsión de algunos se justificó por su calidad de franceses, caso de Beltrán Dovat; pero otros, que ni eran franceses ni enemigos, también fueron obligados a abandonar el Señorío.

Atendiendo a los datos de archivo, observamos cómo de un total de 53 casos tomados en consideración, la mayoría (16, es decir, el 30\%) siguen aludiendo a cuestiones de deudas, como por ejemplo, el testimonio del sueco Lars Irenberg, capitán del bergantín "María Catalina", para que Luis Des Essarts, vecino y del comercio de Bilbao, le pagase el lino y el cáñamo que le había traído desde San Petersburgo $^{39}$.

En segundo término según su importancia, es preciso referirse a las protestas de mar y averías que se ejecutan en estos años, las cuales, como ya hemos citado, están relacionadas directamente con las dificultades para la navegación que tanto marineros como comerciantes ven sucederse a fines del siglo XVIII. Así, frente a las tres protestas que registramos por ejemplo de 1715-1735 o las cinco entre 17551770 destacan los cerca de quince desde 1785 y 1800. Entre éstas, merecen citarse dos expedientes de varamento y naufragio de bergantines, que ocurren el 20 de febrero de 1785 y el 21 de noviembre de 1786. El primero de los cuales hace referencia a la nave "Dulce Nombre de Jesús", encallada en los arenales de Plencia, y cuyo patrón era Agustín Posse de Comillas ${ }^{40}$ (días más tarde, el corregidor recibirá el expediente de naufragio de dicho bergantín ${ }^{41}$ ); el segundo, alude al barco "Hércules", mandado por el capitán inglés Robert Mills y procedente de San Juan de Terranova con carga de bacalao, a la consignación de la compañía "Dovat, Labat y Plante", de Bilbao. Su naufragio se produjo días más tarde en las Peñas del Cuervo de Portugalete ${ }^{42}$.

El tercer asunto en importancia son los sucesos relacionados con la violencia, tanto física y psíquica como material (hurtos), relacionados ya más contundentemente con reacciones xenofóbicas claras hacia el colectivo galo. Algunas muestras de ello son: la causa criminal del 19 de junio de 1789, poco después de haberse iniciado la Revolución, contra el peluquero de la Villa Mariano de las Heras, y sus adláteres, declarados en rebeldía, a causa de las lesiones ocasionadas a Francisco de Tombeur, soldado francés de la Séptima Compañía del

\footnotetext{
39 A.F.V., Sección Judicial, Corregimiento, leg. 1924 / 022.

40 A.F.V., Sección Judicial, Corregimiento, leg. 2174 / 007.

41 A.F.V., Sección Judicial, Corregimiento, leg. 0558 / 009.

42 A.F.V., Sección Judicial, Corregimiento, leg. 1151 / 043.
} 
Segundo Batallón de blancos del regimiento de infantería de Flandes ${ }^{43}$; o dos acusaciones de estupro esgrimidas contra franceses en 1790 y 1791, a las que hay que sumar otras en 1796 y $1799^{44}$.

A pesar de este incuestionable rechazo y de las leyes que impiden la venida e incluso la estancia a los franceses, muchos de ellos, quizás temiendo los excesos de la Convención jacobina y su aplicación indiscriminada del Terror a los considerados como "enemigos" de la Revolución ${ }^{45}$, siguieron acudiendo en busca de refugio. Léanse en este aspecto los autos del 27 de marzo de 1793 promovidos por José Pablo Mauvoissin Cardonne, para que pudiera acogerse a las concesiones otorgadas por Cédula Real a los refugiados franceses ${ }^{46}$. Precisamente el mismo día, el violinista de profesión Juan Armingaud, domiciliado en Bayona y residente en Bilbao, presentó una lista de testigos con la que acreditaba su "buena conducta y costumbres cristianas", a fin de que no se le aplicaran las Reales Provisiones referentes al extrañamiento de franceses no domiciliados en los reinos de España ${ }^{47}$.

\section{8-1814}

José I tuvo en España ciertamente seguidores leales (entre ellos, los afrancesados), numerosos colaboradores y, desde luego, muchos más enemigos que amigos. En opinión de Pilar Feijoó Caballero, ese mismo proceso se vivió también en Vizcaya, donde se vive y se muere entre lealtades, guerra, revolución, bandidismo... ${ }^{48}$. Y es que en el Señorío, ya desde enero de 1808, las tropas de Napoleón quedaron acantonadas en varios enclaves, entre los cuales están Orduña, Elorrio, Durango, Mondragón y Eibar. El resto sería ocupado con celeridad, si bien a lo largo del mismo año, la ciudad cambiaría varias veces de manos hasta que entre agosto y noviembre, pasó a ser "francesa" definitivamente. El vecindario bilbaíno se mostró dividido: la mayor parte de la clase dirigente, las gentes más

${ }^{43}$ A.F.V., Sección Judicial, Corregimiento, leg. 1194 / 009.

${ }^{44}$ A.F.V., Sección Judicial, Corregimiento, leg. 1006 / 003; 0177 / 012; 1042 / 043; y 0254 / 007. Resulta curioso observar la relativa ausencia de denuncias por estupro en los dos periodos anteriores (tan sólo hemos hallado un caso en cada uno de ellos), respecto a estos "turbulentos y agitados" años, en los que en el plazo de nueve años, se contabilizan cuatro, todas contra franceses.

${ }^{45}$ Es sintomático ver cómo el argumento contrario, es decir, el ser agentes de la Revolución, será utilizado (independientemente de que sea verdadero o falso) contra los galos para lograr su expulsión del Señorío (ver caso de Beltrán Dovat).

${ }^{46}$ A.F.V., Sección Judicial, Corregimiento, leg. 0830/003.

${ }^{47}$ A.F.V., Sección Judicial, Corregimiento, leg. 0408 / 031.

${ }^{48}$ Feijoó CABALlERO, P. (1989). "Guerra de la Convención y Guerra..., p. 26 
ricas y los más poderosos comerciantes, no ocultaron su afección a los Bonaparte; el pueblo y gentes de toda condición tampoco ocultaron su animadversión contra los galos y, alentados por el espíritu de rebelión existente en tantos lugares de España, decidieron luchar a favor de Fernando VII. Según la autora citada anteriormente, "esto se explica porque creyeron asegurar su futuro si vencían al francés: los revoltosos estaban en el error de que se haría la paz con Inglaterra, y se abriría el comercio del cual dependía toda aquella gente"49.

Pasando al aspecto judicial, de un total de 21 casos, 9 están relacionados con la guerra contra Francia, es decir, el acontecimiento que marca la coyuntura del periodo. Perfecta expresión del rechazo hacia las tropas invasoras son las expresiones de ira popular que, como en el resto de España, se dan en estos momentos. Para ilustrarlo, tenemos lo acaecido el 9 de diciembre de 1808, cuando Francisco Plácido de San Millán, vecino de la anteiglesia de Abadiano, Juan Antonio de Requeta, Francisco de Echebarria y Pedro González Zárate mataron a tiros a un soldado húsar de la partida apostada en la villa de Durango. También están los autos criminales promovidos por el mismo Tribunal el 24 de enero de 1810 en relación al asesinato de un oficial y dos soldados franceses en Guerricáiz ${ }^{50}$.

Estas reacciones de la gente se explican en cierto sentido, además de por este rechazo generalizado, por otras acciones de menor envergadura, pero igualmente irritantes; aquí entran la demanda promovida por el vecino de Berango Juan de Egusquiza el 5 de enero de 1809, contra la anteiglesia de Berango y sus regidores, sobre la satisfacción de unos bueyes y el carro que le quitaron unos soldados franceses $^{51}$; o el pleito del 30 de junio de 1813, en el que Ignacio Arribilaga, vecino del valle de Orozco, protestó contra la localidad para que se le restituyera el importe de dos mulas que había perdido trabajando de bagajero para el ejército del general Soulier ${ }^{52}$. Menos de un mes después, el 23 de julio, el Corregidor del Señorío solicitó información sobre el robo efectuado por las tropas francesas, ya en

${ }^{49}$ Feijoó CABAllero, P. (1989). “Guerra de la Convención y Guerra..., p. 28

50 A.F.V., Sección Judicial, Corregimiento, legs. 0582 / 002 y 1142 / 019 respectivamente.

${ }^{51}$ Recuérdese aquí la postura filofrancesa de las autoridades, en oposición al apego popular hacia "el deseado" Fernando VII. Este caso está contenido en A.F.V., Sección Judicial, Corregimiento, leg. 1349 / 004.

52 A.F.V., Sección Judicial, Corregimiento, leg. 1711 / 016. El general Soulier había sido enviado por Napoleón a la Península en 1812, concretamente al ámbito navarro, con el fin de hacer frente a las fuerzas guerrilleras del famoso Espoz y Mina. A esta fuerza contrainsurgente de unos 30.000 hombres, se le conoce como "los infernales de Soulier". 
retirada, en el peaje del camino real de Ermua, sobre el depósito recaudado por Alejo de Cortázar, vecino de la villa de Placencia, Guipúzcoa ${ }^{53}$.

De una importancia menor serán los pleitos registrados por impagos, promovidos por particulares, y no tanto por las compañías comerciales que funcionaron en el siglo anterior, prácticamente extinguidas ahora. Por ejemplo, el expediente promovido en agosto de 1814 por el italiano residente en Bilbao Juan Galfeti, contra otro italiano, Juan Pedone, sobre la paga de 46 libras esterlinas y 4 chelines procedentes de diversos catalejos, naranjas y otros artículos ${ }^{54}$.

En definitiva, la mayoría de casos judiciales que se van a promover en los cuatro marcos cronológicos estudiados, comúnmente atañen a aspectos de impagos de deudas, letras de cambio no abonadas, fletes que aún no han sido satisfechos,... $Y$ es que si a los españoles no les agradaba en exceso ver a extranjeros al frente del gobierno (lo que ciertamente no fue una excepción en el XVIII), menos aún les gustaba que se erigieran en competencia en el aspecto económico: a los comerciantes, entre ellos los bilbaínos, porque veían crecer la concurrencia; a los artesanos, porque peligraban sus trabajos ante la privilegiada producción foránea; y a los jornaleros, porque descendían sus salarios con la presencia de trabajadores temporeros extranjeros. A pesar de esta doble reticencia (política y económica), tampoco se puede afirmar que la intransigencia fuera absoluta, si bien el caso de los franceses fue especial.

En segundo lugar en cuanto al número, que no en cuanto a su importancia, merecen citarse los casos de violencia, entendida ésta como robos, amenazas, injurias, agresiones físicas y en última instancia, el asesinato. En general, apreciamos en la mayor parte del siglo XVIII una convivencia con ciertas estridencias, pero sin más animosidad. Los problemas se tornarán importantes a finales de la centuria y principios del XIX, cuyo origen está en la masiva afluencia de exiliados franceses debido a la eclosión de la Revolución ${ }^{55}$. En este momento,

53 A.F.V., Sección Judicial, Corregimiento, leg. 0553 / 003.

${ }^{54}$ A.F.V., Sección Judicial, Corregimiento, leg. 1087 / 033.

${ }^{55}$ Con el estallido revolucionario, numerosos emigrantes llegaron a la villa de Bilbao en cantidad aproximada de mil treinta religiosos y otros tantos civiles. Se trataba de gentes muy dispares, ya que iban desde los mendigos, gentes sin trabajo o sin oficio hasta cientos de exiliados políticos, clérigos y seglares, del proceso revolucionario iniciado en 1789. Como consecuencia de ello, la situación se enquistó, llegándose a producir violentas protestas populares contra las autoridades provinciales y el Corregidor. Feijoó CABAllero, P. (1995). Bizkaia y Bilbao en tiempos de la Revolución francesa. Bilbao: Diputación Foral de Bizkaia, p.164; según los datos de los Libros de Decretos del 21 de octubre de 1792. 
autores como Pilar Feijoó hablan abiertamente de xenofobia, encontrando en las fuentes hechos que así lo atestiguan. Mención especial merece el caso de la Guerra de la Independencia, período este en el que la animadversión hacia los ejércitos galos de los generales Merlín y Soulier se materializó, como vimos, en varios homicidios y acciones violentas contra ellos; e igualmente, en quejas por parte de los campesinos como consecuencia de las "razzias" y saqueos, casi siempre a medio camino entre la "legalidad" (pues contaron con el apoyo de ciertas autoridades de la Villa durante algún tiempo), y la imposición; que llevaron a cabo durante los años comprendidos entre 1808 y 1814.

En lo que respecta a la respuesta por parte de las autoridades, ésta osciló entre la necesidad que se tenía de los extranjeros como fuente del necesario crecimiento económico en el caso de técnicos y menestrales y el rechazo hacia los comerciantes y financieros, los cuales contribuían a sacar el numerario hacia las arcas de potencias exteriores. En este difícil equilibrio y sabedores de la postura más o menos contraria de la población hacia los extranjeros, la política de las autoridades fue moderar la entrada de foráneos, abriendo el cupo sólo cuando fuera estrictamente necesario para la marcha de la economía. Cuando se decidía la entrada de un número determinado de extranjeros, siempre se establecieron dos condiciones indispensables. Por un lado, los aspirantes debían profesar la religión católica como condición "sine qua non" para poder afincarse en el país. Por otro lado, se estableció una especie de distinción social, es decir, que los inmigrados no fueran las clases más bajas o grupos marginales de los otros países, hecho este que, como veremos, no se cumplió, pues ni el Hospital ni la Casa de Misericordia establecida en Bilbao contaron con capacidad para asumir el flujo de pobres y mendigos $^{56}$.

La documentación oficial de que disponemos se refiere fundamentalmente al marco temporal que va de la Guerra de la Convención al final de la Guerra de Independencia, y hace especial hincapié en el componente francés, que fue el más importante contingente poblacional foráneo durante los siglos XVII y XVIII, aumentando su intensidad desde la década de 1790. Sin embargo, podemos esbozar algunos aspectos anteriores a este periodo gracias a la documentación proporcionada por Larrea y Mieza ${ }^{57}$. Así, encontramos una serie de medidas, a nuestro juicio, bastante significativas, como la del 13 de diciembre de 1728 ,

${ }^{56}$ Feijoó Caballero, P. (1995). Bizkaia y Bilbao en tiempos..., p. 146-151.

${ }^{57}$ LARrea, M. A. y MiezA, R. (1992). Legislación foral del Señorío de Vizcaya (1528-1877): registro de los actos legislativos dispuestos por las Juntas del Señorio, sus Regimientos y Diputaciones Generales. Bilbao: Universidad de Deusto. 
cuando la Junta General decidió suplicar al Consejo de Castilla la necesidad de que éste castigase a los extranjeros que pretendían disfrutar de los mismos honores que los naturales. Más expeditiva se muestra la Diputación General el 15 de abril de 1746 al dictaminar que los forasteros que residieran en el Señorío sin haber manifestado intento alguno de justificar sus genealogías, debían presentar la documentación en el plazo de dos meses; de no hacerlo, se procedería a su expulsión. De ello deducimos que ya antes del movimiento anti-extranjero (y en especial anti-francés) de finales de siglo, existía, cuando menos, un evidente recelo hacia los foráneos, ejerciendo contra ellos una serie de medidas de control bastante estrictas $^{58}$.

En relación con la ingente inmigración francesa que huía de la Revolución, ya hemos comentado la heterogeneidad de la masa entrante, cuyo principal efecto fue agudizar los más o menos latentes sentimientos hostiles de la población a lo largo del siglo que tocaba a su fin. Las protestas de los ciudadanos obligaron al Ayuntamiento a tomar cartas en el asunto, que optó por la salida más rápida: la expulsión de los extranjeros. Esta primera medida afectó a la masa de pobres que se dedicaban a la mendicidad o que desempeñaban ocasionalmente algún tipo de oficio. La decisión pareció surtir efecto ${ }^{59}$; sin embargo, no serían los más menesterosos las últimas víctimas, puesto que igualmente a comerciantes y artesanos foráneos, especialmente los franceses, se les ofreció dos alternativas: abandonar la Villa o presentar la documentación necesaria para su inmediato avecindamiento. Parece, pues, que aquí se aprovechó la coyuntura para "satisfacer la muy vieja xenofobia bilbaína y, en los intentos de expulsión, quedaron incluidos no sólo los franceses, sino también ingleses y españoles de muy diversas procedencias ${ }, 60$.

En 1793, una Provisión Real dada por Carlos IV mandaba la expulsión de los franceses no domiciliados en estos reinos; el mismo año, una Cédula Real ordenaba la creación de un tribunal denominado como "Junta de Represalias", encargado de los asuntos concernientes al secuestro de los bienes de los franceses expulsados y de las indemnizaciones que les correspondían; en 1794, otra Provisión Real excluía

${ }^{58}$ A las citadas medidas podemos añadir la Real Cédula expedida por Carlos III en 1764 para que anualmente se formase en todos los puertos y lugares de comercio una lista de comerciantes y demás personas extranjeras, especificando si se trataba de transeúntes o de vasallos de Su Majestad.

59 Así lo atestigua Jovellanos, que al visitar Bilbao en 1791, confirmó la ausencia de pobres. Feijoó CABAllero, P. (1995). Bizkaia y Bilbao en tiempos..., p. 212.

${ }^{60}$ Feijoó CABAllero, P. (1995). Bizkaia y Bilbao en tiempos..., p. 254. 
a los franceses de los oficios públicos ${ }^{61}$. Bastaba pues con argüir que los galos eran agentes de la Revolución para lograr su salida del Señorío. Este fue el argumento utilizado por los notables de Bilbao contra algunos poderosos hombres de negocios franceses con el fin de desembarazarse de estos importantes competidores, caso del anteriormente tratado Beltrán Douvat ${ }^{62}$.

Un Decreto Real de 2 de abril de 1798 por parte de Carlos IV, mandaba expulsar a los emigrantes franceses del Señorío con el fin de evitar que continuasen ocasionando desórdenes públicos. Para no negarles enteramente la hospitalidad, se resolvió asimismo que fuesen enviados a la isla de Mallorca, debiéndose presentar en Barcelona en el término de 30 días. Los emigrados y deportados que no llevaron a cabo esta orden, fueron impelidos de nuevo al año siguiente, 1799, por la cual serían conducidos en esta ocasión a Mallorca (vía Barcelona), o a las Canarias (vía La Coruña) ${ }^{63}$. Lógicamente, la firma de la paz con los franceses en 1795, trajo como consecuencia la declaración de guerra a Inglaterra; estableciéndose la expulsión de los ingleses que residían en esta jurisdicción (salvo aquellos que ya se hubieran avecindado o que se dedicasen a oficios mecánicos) el 22 de octubre de $1796^{64}$.

Refiriéndonos ahora al período de la Guerra de la Independencia, 1808-1814; ya en el mismo año de la llegada de los galos a la Península, el mismo Carlos IV, como consecuencia de lo resuelto por el gobierno británico declarando en estado de bloqueo todas las costas de Francia, España y sus aliados, manda observar la misma conducta para con las Islas Británicas y con cualquier embarcación registrada por los ingleses ${ }^{65}$. Igualmente, y ya por orden de Napoleón (tras hacerse con el poder político del país), se mandó secuestrar todas las mercancías de

${ }^{61}$ A.F.V. , Sección Bilbao Antigua, fondo municipal, legajo 0323 / 001 / 006; 0323 / 001 / 011; y $0323 / 001 / 019$ respectivamente.

${ }^{62}$ Como vimos, ni él ni su hermano se avecindaron nunca a pesar de las presiones que en 1773 recibieron por parte de la Diputación. Aun cuando ambos lograron la venia real para su estancia, las autoridades continuaron porfiando para lograr su objetivo, pero la apelación presentada dos años después ante el Consejo de Castilla resultó infructuosa. La inquina hacia ellos se manifestó nuevamente en la década de 1790, aludiendo a su supuesta condición de agente de la Revolución, además de albergar, también supuestamente, en su casa un club jacobino y de poner en peligro la seguridad del Señorío. La presión surtió efecto y Carlos IV ordenó en 1792 encarcelar a Douvat, quien posteriormente fue desterrado.

63 A.F.V., Sección Bilbao antigua, fondo municipal, leg. 0276/001/061 y 0277/001/006.

64 A.F.V., Sección Bilbao antigua, fondo municipal, leg. 0276/001/033.

65 A.F.V., Sección Bilbao antigua, fondo municipal, leg. 0282/001/001. 
fabricación inglesa o efectos coloniales pertenecientes a británicos ${ }^{66}$. Pero estas medidas, consecuencia de la dominación norpirenaica en la Península, cambiarán radicalmente a medida que la resistencia hispana y la hegemonía napoleónica entraron en un irremisible declive. Efectivamente, en 1813, la Regencia del Reino manda cumplir el decreto de las cortes extraordinarias por el que se dispone que los franceses y naturales de los países sujetos a Napoleón, debían salir del Reino, aunque con algunas excepciones ${ }^{67}$. No obstante, el temor continúa hacia Bonaparte, especialmente durante su retorno a la escena política europea durante el denominado Imperio de los Cien Días, lo que es evidenciable en la Orden Real de Fernando VII de 1815 , por la que se ordena a todas las autoridades militares, políticas y eclesiásticas, que velen con la mayor "cautela y precaución" con el objeto de evitar cualquier "sorpresa" por parte de los partidarios de Napoleón ${ }^{68}$. Aunque al fin, pasada la quimérica aventura neobonapartista, Fernando VII permitirá de nuevo las relaciones comerciales con Francia, una vez restituido en el trono Luis XVIII ${ }^{69}$. Restablecidas las relaciones con el país vecino y devuelto el orden al concierto internacional europeo tras el Congreso de Viena, la diplomacia entre Inglaterra y España volvió a sus cauces. Así, por Orden Real de 1815, se manda que todos los buques de la Marina británica que arribaran a los puertos de la Península, fuesen recibidos "amistosamente" $"$.

En definitiva, en el lapso temporal que ha sido objeto de nuestro análisis, la xenofobia puede apreciarse de un modo claro en esos momentos de amenaza externa importante para la comunidad local, muchas veces reticente al cambio, así como por parte de las autoridades públicas en defensa del orden establecido frente

66 A.F.V., Sección Bilbao Antigua, fondo municipal, leg. 0282/001/040.

67 A.F.V., Sección Bilbao Antigua, fondo municipal, leg. 0282/001/076. Concretamente, se les permitiría la permanencia a aquéllos que, a juicio de los Ayuntamientos, hubieran hecho servicios importantes o dado muestras de su identificación con "la justa causa de la Nación"; a los que el Gobierno expidiera una licencia temporal, ampliable y revocable; a los que antes del comienzo de la Guerra de Independencia se hallasen inscritos en las matrículas de los Cónsules franceses y deseasen permanecer en el Reino; a todos los que hicieron juramento de fidelidad al Gobierno español o hubiesen adquirido la Carta de Naturaleza o el permiso de avecindamiento conforme a las leyes; a los súbditos de las potencias dependientes de Francia o que hubieses aportado contingentes a los franceses, siempre que cumplieran las condiciones de naturaleza o vecindad; y a los franceses huidos de su país y venidos en busca de protección a la Península, quedando su admisión en manos del gobierno, que debía "conciliar lo que reclama la humanidad con lo que exige la seguridad del Estado y la conservación del orden público".

68 A.F.V., Sección Bilbao Antigua, fondo municipal, leg. 0283/001/032.

69 A.F.V., Sección Bilbao Antigua, fondo municipal, leg. 0283/001/048.

70 A.F.V., Sección Bilbao Antigua, fondo municipal, leg. 0283/001/030. 
a alteraciones bruscas como la derivada de la Revolución burguesa de 1789 o la Guerra de la Independencia. Mientras tanto, en períodos más o menos tranquilos la convivencia y la vida cotidiana de la población se hizo relativamente llevadera, pero siempre teniendo presente que el entusiasmo hacia la presencia de los extranjeros no fue la tónica dominante, pues los comerciantes foráneos hacían una dura competencia a los locales, disminuyendo su negocio. Los artesanos veían cómo con un mayor número de trabajadores potenciales recortaban los salarios, mientras que en situaciones de hambres y carestías había más bocas que alimentar, creciendo sensiblemente el número de mendigos e indigentes. 